\title{
PARTISIPASI ANGGOTA KELOMPOK WANITA TANI (KWT) DALAM PROGRAM KAWASAN RUMAH PANGAN LESTARI (KRPL) DI KECAMATAN BOGOR BARAT KOTA BOGOR
}

\author{
S. Masithoh ${ }^{1 \mathrm{a}}$, H. Miftah ${ }^{1}$, A. Aina ${ }^{1}$ \\ ${ }^{1}$ Jurusan Agribisnis, Fakultas Pertanian Universitas Djuanda Bogor \\ Jalan Tol Ciawi No. 1 Kotak Pos 35 Bogor 16720 \\ ${ }^{a}$ Korespondensi: Siti Masithoh. Telp: 0817404974; E-mail: smasithoh@ yahoo.com
}

\begin{abstract}
This research was aimed to know the implementation of kawasan rumah pangan lestari (KRPL) programs, to know the participation level and the factors that influences at Kecamatan Bogor Barat, Kota Bogor. Research conducted in KWT Mawar, Gapura Ning Rahayu, Mahkota Dewa dan Geulis, by taking 55 samples of women farmers. Spearman correlation analyses were conducted by using SPSS 16 application. The stages of the member KWT participation on the KRPL program divided into 4 : planning, implementation, utilization, and evaluation. The results showed that participation of the women farmers are high (total score 6443, average score 2,62). But, there are the different result for the different stages (middle participation at planning and utilization stages, high participation at implemetation and evaluation stages). Based on the spearman correlation analysis, the women farmers participation are affected by family supporting, availability of equipment (sarana dan prasarana) and education level. Factors most stongly correlatied is family supporting (correlation coefficient is 0,635 )
\end{abstract}

Keywords: particiption level, women farmers, KRPL, Spearman Correlation

\begin{abstract}
ABSTRAK
Penelitian ini bertujuan untuk mengetahui pelaksanaan program kawasan rumah pangan lestari (KRPL) secara konsep maupun praktek, mengetahui tingkat partisipasi serta mengetahui faktor-faktor yang mempengaruhi serta berhubungan dengan tingkat partisipasi. Penelitian ini dilaksanakan pada Bulan Februari 2014. Analisis yang digunakan adalah analisis korelasi Rank Spearman. Tahapan partisipasi anggota KWT dalam Program KRPL dibagi kedalam empat tahapan yaitu : tahap perencanaan, tahap pelaksanaan, tahap manfaat dan tahap evaluasi. Hasil penelitian dari 55 responden menunjukan bahwa tingkat partisipasi termasuk tinggi dengan jumlah skor 6443 dengan rataan skor 2,62 . Tetapi didalam empat tahapan itu beragam hasilnya yaitu dalam tahap perencanaan partisipasi sedang, tahap pelaksanaan partisipasi tinggi, tahap manfaat partisipasi sedang dan tahap evaluasi partisipasi tinggi. Faktor-faktor yang berhubungan nyata dengan tingkat partisipasi adalah dukungan keluarga, ketersediaan sarana dan prasarana dan tingkat pendidikan. Faktor yang berhubungan paling kuat adalah dukungan keluarga dengan nilai korelasi 0,635.
\end{abstract}

Kata kunci : Tingkat partisipasi, Wanita tani, Pekarangan, dan Faktor pengaruh partisipasi. 


\section{PENDAHULUAN}

Kementrian Pertanian pada Tahun 2013 menyusun suatu konsep yang disebut dengan Model Kawasan Rumah Pangan Lestari (Model KRPL) yang merupakan himpunan dari Rumah Pangan Lestari (RPL) yaitu rumah tangga dengan prinsip pemanfaatan pekarangan yang ramah lingkungan dan dirancang untuk pemenuhan kebutuhan pangan dan gizi keluarga, diversifikasi pangan berbasis sumber daya lokal, pelestarian tanaman pangan untuk masa depan, serta peningkatan pendapatan yang pada akhirnya akan meningkatkan kesejahteraan masyarakat. (Badan Litbang Pertanian, 2012).

Kota Bogor merupakan salah satu kota di Jawa Barat yang mendapat program KRPL Tahun 2013 sebanyak empat belas kelompok wanita tani yang tersebar di empat belas kelurahan. Kecamatan Bogor Barat mendapat. Program KRPL sebanyak empat kelompok di empat kelurahan yaitu Kelurahan Menteng, Cilendek Barat, Bubulak dan Situ Gede (Kantor Ketahanan Pangan Kota Bogor, 2013).

Pada penerapannya, partisipasi masyarakat menjadi unsur terpenting dalam pelaksanaan RPL. Menurut Azis (2009), pengertian prinsip partisipasi adalah masyarakat berperan secara aktif dalam proses atau alur tahapan program dan pengawasannya, mulai dari tahap sosialisasi, perencanaan, pelaksanaan, dan pelestarian kegiatan dengan memberikan sumbangan tenaga, pikiran, atau dalam bentuk materiil. Oleh karena itu, diperlukan pengkajian mengenai tingkat partisipasi wanita tani dalam program Kawasan Rumah Pangan Lestari (KRPL).

Kementerian

Pertanian menginisiasi optimalisasi pemanfaatan pekarangan melalui konsep Rumah Pangan Lestari (RPL). RPL adalah rumah penduduk yang mengusahakan pekarangan secara intensif untuk dimanfaatkan dengan berbagai sumberdaya lokal secara bijaksana yang menjamin kesinambungan penyediaan bahan pangan rumah tangga yang berkualitas dan beragam (Badan Litbang Pertanian, 2012).

Program KRPL sudah berjalan kurang lebih satu tahun, namun seiring berjalannya program ternyata dilapangan program masih belum optimal. Anggota kelompok belum dapat menambah pendapatan keluarga dari hasil pemanfaatan lahan pekarangan.

Oleh karena itu, sangat penting masalah penelitian tentang kawasan rumah pangan lestari (KRPL) ini dilaksanakan karena partisipasi anggota KWT merupakan unsur terpenting dalam pelaksanaan rumah pangan lestari yang tentunya berperan secara aktif dalam alur tahapan programnya.

Berdasarkan uraian tersebut diatas, maka yang menjadi masalah dalam penelitian ini adalah (1) Bagaimana pelaksanaan program Kawasan Rumah Pangan Lestari (KRPL) secara konsep maupun praktek dilapangan (2) Bagaimana karakteristik anggota kelompok wanita tani penerima program KRPL di Kecamatan Bogor Barat (3) Bagaimana partisipasi anggota kelompok wanita tani dalam kegiatan KRPL di Kecamatan Bogor Barat (4) Faktor-faktor apa saja yang berhubungan dengan tingkat partisipasi anggota kelompok wanita tani dalam kegiatan KRPL.

Tujuan penelitian ini adalah:

1. Mengetahui pelaksanaan program kawasan rumah pangan lestari (KRPL) secara konsep maupun praktek

2. Mengkaji karakteristik anggota kelompok wanita tani penerima program kawasan rumah pangan lestari (KRPL) di Kecamatan Bogor Barat.

3. Mengkaji partisipasi anggota kelompok wanita tani dalam kegiatan KRPL di Kecamatan Bogor Barat.

4. Mengetahui faktor-faktor yang berhubungan dengan tingkat partisipasi. 


\section{BAHAN DAN METODE}

\section{Pengertian Partisipasi}

Mardikanto (1991) menyatakan bahwa, partisipasi merupakan suatu bentuk khusus dari interaksi dan komunikasi yang berkaitan dengan pembagian: kewenangan, tanggung jawab, dan manfaat. Tahapantahapan partisipasi adalah sebagai berikut :

$\begin{array}{lll}\text { 1. } & \text { Tahap partisipasi } & \text { dalam } \\ \text { pengambilan keputusan } & \\ \text { 2. } & \begin{array}{l}\text { Tahap partisipasi } \\ \text { perencanaan kegiatan }\end{array} \\ \text { 3. dalam } & \\ \text { Tahap partisipasi } & \text { dalam } \\ \text { pelaksanaan kegiatan } & \\ \text { 4. } & \begin{array}{l}\text { Tahap partisipasi dalam } \\ \text { pemantauan dan evaluasi kegiatan }\end{array} \\ \text { 5. } & \begin{array}{l}\text { Tahap partisipasi } \\ \text { pemanfaatan hasil kegiatan }\end{array} \\ & \end{array}$

\section{Pengertian Kelompok Wanita Tani}

Kelompok wanita tani menurut Departemen Pertanian (1996) adalah kumpulan istri petani atau wanita tani yang bersepakat membentuk suatu perkumpulan yang mempunyai tujuan yang sama dalam membantu kegiatan usaha pertanian, perikanan dan kehutanan untuk meningkatkan pendapatan dan kesejahteraan keluarganya.

\section{Pengertian Kawasan Rumah Pangan Lestari (KRPL) \\ KRPL adalah sebuah konsep} lingkungan perumahan penduduk yang secara bersama-sama mengusahakan pekarangannya secara intensif untuk dimanfaatkan menjadi sumber pangan secara berkelanjutan dengan mempertimbangkan aspek potensi wilayah dan kebutuhan gizi warga setempat. (Badan Ketahanan Pangan 2013).

Sisi lain dari program KRPL adalah berlangsungnya pemanfatan sumberdaya pangan lokal, berkembangnya kuliner berbasis pangan lokal, dan secara tidak langsung ikut serta mengelola dan memelihara sumberdaya genetik lokal (bermacam-macam ubi, buah langka, sayuran, kacang-kacangan, tanaman obat).
Ruang Lingkup Program Kawasan Rumah Pangan Lestari

Optimalisasi

pemanfaatan

pekarangan dilakukan melalui upaya pemberdayaan wanita untuk mengoptimalkan mafaat pekarangan sebagai sumber pangan keluarga. Kelompok sasaran kegiatan optimalisasi pemanfaatan pekarangan melalui konsep KRPL adalah kelompok wanita yang beranggotakan minimal 30 rumah tangga yang berdomisili berdekatan dalam satu desa.

\section{Pekarangan}

Pekarangan menurut Badan Ketahanan Pangan (2013) adalah lahan yang ada disekitar rumah dengan batas pemilikan yang lebih jelas (lahan boleh berpagar dan boleh tidak berpagar) serta menjadi tempat tumbuhnya berbagai jenis tanaman dan tempat memelihara berbagai jenis ternak dan ikan.

\section{Tanaman Pekarangan}

Tanaman pekarangan menurut Badan Ketahanan Pangan (2013) adalah tanaman yang menghasilkan umbi, buah, sayuran, bahan obat nabati, florikultura, termasuk didalamnya jamur, lumut, dan tanaman air yang berfungsi sebagai buah, sayuran, bahan obat nabati, dan atau bahan estetika.

\section{Waktu dan Lokasi}

Penelitian ini dilaksanakan di Kecamatan Bogor Barat, Kota Bogor. Lokasi ini dipilih secara purposive sampling dengan pertimbangan bahwa di kecamatan ini terdapat kelompok wanita tani penerima program KRPL terbanyak se-Kota Bogor. Penelitian dilaksanakan pada bulan Februari 2014.

\section{Jenis dan Sumber Data}

Data yang digunakan dalam penelitian ini adalah data primer dan data sekunder. Data primer diperoleh dengan cara observasi langsung ke lokasi penelitian dan mengadakan wawancara 
langsung dengan responden menggunakan daftar pertanyaan (kuesioner) yang telah disusun sesuai dengan tujuan penelitian.

Data sekunder adalah data yang diperoleh dari studi kepustakaan, Kantor Kelurahan Menteng, Cilendek Barat, Bubulak dan Situ Gede, Kecamatan Bogor Barat, Programa Penyuluhan Pertanian Kecamatan Bogor Barat serta sumbersumber lain yang mendukung penelitian ini.

\section{Metode Pengambilan Sampel}

Populasi yang digunakan adalah anggota kelompok wanita tani (KWT) penerima program KRPL sebanyak 120 orang. Nama KWT tersebut adalah Mawar, Gapura Ning Rahayu, Mahkota Dewa dan Geulis.

Metode pengambilan sampel yang digunakan dalam penelitian ini adalah Purposive sampling. Besarnya jumlah sampel dan mengingat keterbatasan waktu dalam melakukan penelitian maka dilakukan penarikan sampel yang dapat mewakili populasi secara keseluruhan. Untuk menentukan banyaknya sampel dalam penelitian ini maka digunakan rumus perhitungan Slovin dalam Sugiyono (2011) sebagai berikut:

$$
\mathrm{n}=\frac{\mathrm{N}}{1+\left(\mathrm{N} \mathrm{x} \mathrm{e}^{2}\right)}
$$

Keterangan :

$\mathrm{n}$ : Jumlah sampel yang dicari

$\mathrm{N}$ : Jumlah populasi

e : Presentase kelonggaran kesalahan $(10 \%)$

1 : Nilai Konstan

Dengan menggunakan rumus tersebut maka jumlah sampel dalam penelitian ini adalah sebagai berikut :

$$
\begin{aligned}
& \mathrm{n}=\frac{\mathrm{N}}{1+\left(\mathrm{N} \mathrm{x} \mathrm{e}^{2}\right)} \\
& \mathrm{n}=\frac{120}{1+\left(120 \times 10 \%^{2}\right)} \\
& \mathrm{n}=54,54 \text { dibulatkan menjadi } 55 \\
& \text { orang. }
\end{aligned}
$$

\section{Metode Analisis Data}

Data yang diperoleh diolah dan dianalisis dengan menggunakan analisis deskriptif. Analisis tingkat partisipasi dan faktor-faktor yang mempengaruhi diukur dengan metode kuantitatif dengan menggunakan skala Likert. Hubungan antara tingkat partisipasi dengan faktorfaktor yang mempengaruhi partisipasi dianalisis menggunakan korelasi Rank Spearman.

\section{Analisis Deskriptif}

Menurut Sugiyono (2011) metode analisis deskriptif adalah suatu metode dalam meneliti sekelompok manusia, suatu objek, suatu set kondisi, suatu sistem pemikiran ataupun suatu peristiwa pada masa sekarang.

\section{Analisis Likert}

Analisis skala Likert menurut Heru (2008) adalah analisis yang digunakan untuk mengukur sikap, pendapat, dan persepsi seseorang atau sekelompok orang tentang fenomena sosial.

\section{Analisis Korelasi Rank Spearman}

$$
\text { Menurut Sugiyono (2011) }
$$

koefisien korelasi Rank Spearman digunakan untuk mengukur erat atau tidaknya hubungan antara variabel yang diuji dengan menggunakan rumus koefisien korelasi Rank-Spearman. Adapun rumus yang digunakan untuk mencari koefisien Rank Spearman, sebagai berikut:

$$
r=1-\frac{6 \sum d_{i}{ }^{2}}{n\left(n^{2}-1\right)}
$$

Keterangan:

Rs = Koefisien Rank- Korelasi (Spearman) $\mathrm{n}=$ Menunjukan jumlah pasangan observasi dalam sampel

$\Sigma=$ Sigma atau jumlah

$\mathrm{D}=$ Merupakan perbedaan rangking yang diperoleh pada tiap pasangan observasi

Menurut Sugiyono (2011), nilai koefisien korelasi adalah sebagai berikut: 


$$
\begin{aligned}
0,00-0,199 & =\text { Berkorelasi Sangat rendah } \\
0,20-0,399 & =\text { Berkorelasi Rendah } \\
0,40-0,599 & =\text { Berkorelasi Sedang } \\
0,60-0,799 & =\text { Berkorelasi Kuat } \\
0,80-1,000 & =\text { Berkorelasi Sangat Kuat }
\end{aligned}
$$

\section{HASIL DAN PEMBAHASAN}

\section{Gambaran Umum Wilayah Penelitian}

Kecamatan Bogor Barat

merupakan salah satu kecamatan yang terdapat di Kota Bogor. Kecamatan Bogor Barat terdiri atas 16 kelurahan dengan batas wilayahnya yaitu

Sebelah Utara : Kecamatan Kemang

Sebelah Timur: Kecamatan Tanah Sareal

Sebelah Selatan : Kecamatan Ciomas

Sebelah Barat : Kecamatan Dramaga

(Monografi Kecamatan Bogor Barat).

\section{Karakteristik Anggota KWT penerima program KRPL}

Sebagian besar umur responden berusia dewasa yaitu 38-52 tahun berjumlah 34 orang dengan persentase $62 \%$, responden yang berusia tua yaitu 5368 tahun berjumlah 13 orang dengan persentase $24 \%$, dan responden yang berusia muda yaitu 23-37 tahun berjumlah 8 orang dengan persentase $14 \%$ dari seluruh responden.

Semua anggota KWT yang menjadi responden penelitian ini menamatkan pendidikannya. Sebaran tingkat pendidikan responden termasuk kedalam rendah karena dari total responden sebanyak (45\%) anggota KWT mempunyai tingkat pendidikan hanya sampai pada SD. Tamat SMA sebanyak (35\%), tamat SMP sebanyak (16\%) dan mempunyai tingkat pendidikan perguruan tinggi sebanyak (4\%).

Responden yang memiliki anggota keluarga sedikit dengan jumlah anggota keluarga 2-4 orang sebesar (56\%), responden kategori sedang dengan jumlah anggota keluarga 5-7 orang sebesar (38\%), dan responden kategori banyak dengan jumlah $>8$ orang sebesar $(6 \%)$.
Anggota yang sudah menempati rumah tinggal mereka dalam kurun waktu sebelas sampai tiga puluh tahun sebesar (44\%), tiga puluh satu sampai lima puluh tahun sebesar (36\%), limapuluh satu sampai tujuh puluh tahun sebesar (16\%) dan yang kurang dari sepuluh tahun sebesar $(4 \%)$.

\section{Tingkat Partisipasi Anggota KWT dalam Program KRPL di Kecamatan Bogor Barat}

Tahapan partisipasi anggota KWT dalam program KRPL di Kecamatan Bogor Barat dalam penelitian ini dibagi kedalam empat tahap partisipasi yaitu 1). Perencanaan 2). Pelaksanaan 3). Manfaat dan 4). Evaluasi.

Penentuan interval didapatkan dari hasil penghitungan jumlah skor jawaban responden. Jumlah responden sebanyak 55 orang dan tiap responden diberikan sebanyak 38 pertanyaan. Skala jawaban terdiri dari 4 , yang menentukan angka 1 merupakan jawaban yang paling rendah dan 4 jawaban yang paling tinggi.

\begin{tabular}{lcc}
\hline \multicolumn{1}{c}{ Kategori } & Interval & Rataan Skor \\
\hline Rendah & $2090-4179$ & $1-1,66$ \\
Sedang & $4180-6269$ & $1,67-2,32$ \\
Tinggi & $6270-8360$ & $2,33-3,0$ \\
\hline
\end{tabular}

Hasil penelitian dilapangan menunjukan bahwa tingkat partisipasi anggota KWT dalam program KRPL termasuk kedalam kategori tinggi jumlah skor 6443 dengan rataan skor 2,62.

\section{Tingkat Partisipasi Anggota KWT dalam Program KRPL pada Tahapan Perencanaan}

Dari hasil penelitian dilapangan menunjukan bahwa tingkat partisipasi anggota KWT dalam program KRPL pada tahap perencanaan termasuk kedalam kategori sedang jumlah skor 1259 dengan rataan skor 2,31 . 
Tingkat Partisipasi Anggota KWT dalam Program KRPL pada Tahapan Pelaksanaan

Dari hasil penelitian dilapangan menunjukan bahwa tingkat partisipasi anggota KWT dalam program KRPL pada tahap pelaksanaan termasuk kedalam kategori tinggi jumlah skor 2684 dengan rataan skor 2,71 .

Tingkat Partisipasi Anggota KWT dalam Program KRPL pada Tahapan Manfaat

Dari hasil penelitian dilapangan menunjukan bahwa tingkat partisipasi anggota KWT dalam program KRPL pada tahap manfaat termasuk kedalam kategori sedang jumlah skor 908 dengan rataan skor 2,27 .

\section{Tingkat Partisipasi Anggota KWT dalam Program KRPL pada Tahapan Evaluasi \\ Dari hasil penelitian dilapangan menunjukan bahwa tingkat partisipasi anggota KWT dalam program KRPL pada tahap evaluasi termasuk kedalam kategori tinggi jumlah skor 1592 dengan rataan skor 2,73 .}

Faktor-Faktor yang Mempengaruhi Partisipasi Anggota KWT dalam Program KRPL di Kecamatan Bogor Barat

\section{Penyuluh Pendamping}

Penyuluh pendamping merupakan salah satu faktor eksternal yang mempengaruhi anggota KWT dalam program KRPL.

Dari hasil penelitian dilapangan menunjukan bahwa tingkat pengaruh penyuluh pendamping pada anggota KWT dalam program KRPL termasuk kedalam kategori tinggi jumlah skor 1005 dengan rataan skor 2,9 .

\section{Aparat Kelurahan}

Dari hasil penelitian dilapangan menunjukan bahwa tingkat pengaruh aparat kelurahan pada anggota KWT dalam program KRPL termasuk kedalam kategori sedang jumlah skor 252 dengan rataan skor 2,0 .

\section{Dukungan Keluarga}

Dari hasil penelitian dilapangan menunjukan bahwa tingkat pengaruh dukungan keluarga pada anggota KWT dalam program KRPL termasuk kedalam kategori tinggi jumlah skor 368 dengan rataan skor 2,8 .

\section{Ketersediaan Sarana dan Prasarana}

Dari hasil penelitian dilapangan menunjukan bahwa tingkat pengaruh ketersediaan sarana dan prasarana pada anggota KWT dalam program KRPL termasuk kedalam kategori tinggi jumlah skor 558 dengan rataan skor 2,9.

\section{Hubungan umur dengan tingkat partisipasi anggota KWT dalam Program KRPL di Kecamatan Bogor Barat}

Hasil analisis Rank Spearman menunjukkan bahwa umur responden dengan tingkat partisipasi anggota KWT dalam Program KRPL di Kecamatan Bogor Barat memiliki hubungan negatif), Terdapat hubungan yang sangat lemah antara umur dengan tingkat partisipasi dalam program KRPL dengan nilai koefisien korelasi sebesar -0,070. Hasil uji rank spearman juga menunjukkan tidak ada hubungan yang nyata antara umur anggota KWT dengan partisipasi.

Hubungan tingkat pendidikan dengan tingkat partisipasi anggota KWT dalam Program KRPL di Kecamatan Bogor Barat

Hasil analisis Rank Spearman menunjukkan bahwa tingkat pendidikan responden dengan tingkat partisipasi anggota KWT dalam Program KRPL di Kecamatan Bogor Barat memiliki hubungan negatif. Terdapat hubungan yang sedang antara tingkat pendidikan dengan tingkat partisipasi dalam program 
KRPL dengan nilai koefisien korelasi sebesar -0,477. Hasil uji rank spearman juga menunjukkan ada hubungan yang sangat nyata $(\mathrm{p}<0,01)$ antara tingkat pendidikan anggota KWT dengan partisipasi.

Hubungan jumlah anggota keluarga dengan tingkat partisipasi anggota KWT dalam Program KRPL di Kecamatan Bogor Barat

Hasil analisis Rank Spearman menunjukkan bahwa jumlah anggota keluarga responden dengan tingkat partisipasi anggota KWT dalam Program KRPL di Kecamatan Bogor Barat memiliki hubungan positif, maksudnya semakin banyak jumlah anggota keluarga anggota KWT maka partisipasi dalam program KRPL semakin tinggi.

Terdapat hubungan yang sangat rendah antara jumlah anggota keluarga dengan tingkat partisipasi dalam program KRPL dengan nilai koefisien korelasi sebesar 0,119. Hasil uji rank spearman juga menunjukkan tidak ada hubungan yang nyata antara jumlah anggota keluarga anggota KWT dengan partisipasi.

Hubungan penyuluh pendamping dengan tingkat partisipasi anggota KWT dalam Program KRPL di Kecamatan Bogor Barat

Hasil analisis Rank Spearman menunjukkan bahwa penyuluh pendamping dengan tingkat partisipasi anggota KWT memiliki hubungan positif, berarti peran penyuluh pendamping KRPL semakin tinggi maka partisipasi anggota KWT dalam program KRPL semakin tinggi.

Terdapat hubungan yang rendah antara penyuluh pendamping dengan tingkat partisipasi dalam program KRPL dengan nilai koefisien korelasi sebesar 0,212 . Hasil uji rank spearman juga menunjukkan tidak ada hubungan yang nyata antara penyuluh pendamping KRPL dengan partisipasi anggota KWT.
Hubungan peran aparat kelurahan dengan tingkat partisipasi anggota KWT dalam Program KRPL di Kecamatan Bogor Barat

Hasil analisis Rank Spearman menunjukkan bahwa peran aparat kelurahan dengan tingkat partisipasi anggota KWT dalam Program KRPL di Kecamatan Bogor Barat memiliki hubungan positif, berarti peran aparat kelurahan semakin tinggi maka partisipasi anggota KWT dalam program KRPL semakin tinggi. Terdapat hubungan yang sangat rendah antara peran aparat kelurahan dengan tingkat partisipasi dalam program KRPL dengan nilai koefisien korelasi sebesar 0,105. Hasil uji rank spearman juga menunjukkan tidak ada hubungan yang nyata antara aparat kelurahan dengan partisipasi anggota KWT dalam program KRPL di Kecamatan Bogor Barat. Hubungan yang tidak nyata ini berarti ada dan tidaknya aparat kelurahan tidak berhubungan dengan tingkat partisipasi anggota KWT dalam program KRPL.

Hubungan dukungan keluarga dengan tingkat partisipasi anggota KWT dalam Program KRPL di Kecamatan Bogor Barat

Hasil analisis Rank Spearman menunjukkan bahwa dukungan keluarga dengan tingkat partisipasi anggota KWT dalam Program KRPL di Kecamatan Bogor Barat memiliki hubungan positif, berarti dukungan keluarga semakin tinggi maka partisipasi anggota KWT dalam program KRPL semakin tinggi.

Terdapat hubungan yang kuat antara dukungan keluarga dengan tingkat partisipasi dalam program KRPL dengan nilai koefisien korelasi sebesar 0,635. Hasil uji rank spearman juga menunjukkan ada hubungan yang nyata $(\mathrm{p}<0,01)$ antara dukungan keluarga dengan partisipasi anggota KWT dalam program KRPL di Kecamatan Bogor Barat. Hubungan yang nyata ini berarti dukungan keluarga berhubungan dengan tingkat 
partisipasi anggota KWT dalam program KRPL.

Hubungan ketersediaan sarana dan prasarana dengan tingkat partisipasi anggota KWT dalam Program KRPL di Kecamatan Bogor Barat

Hasil analisis Rank Spearman menunjukkan bahwa ketersediaan sarana dan prasarana dengan tingkat partisipasi anggota KWT dalam Program KRPL di Kecamatan Bogor Barat memiliki hubungan positif, berarti semakin tersedia sarana dan prasarana dalam berkegiatan KRPL maka partisipasi anggota KWT dalam program KRPL semakin tinggi.

Terdapat hubungan yang rendah antara ketersediaan sarana dan prasarana dengan tingkat partisipasi dalam program KRPL dengan nilai koefisien korelasi sebesar 0,356. Hasil uji rank spearman juga menunjukkan ada hubungan yang nyata $(\mathrm{p}<0,01)$ antara ketersediaan sarana dan prasarana dengan partisipasi anggota KWT dalam program KRPL di Kecamatan Bogor Barat.

\section{KESIMPULAN DAN IMPLIKASI KEBIJAKAN}

\section{Kesimpulan}

1. Program KRPL di Kecamatan Bogor Barat terdiri dari empat tahapan yaitu tahap perencanaan, pelaksanaan, manfaat dan evaluasi kegiatan. Kegiatan yang dilaksanakan sudah sesuai dengan konsep dalam juknis KRPL yaitu pengembangan demplot kelompok, pengembangan kebun bibit kelompok, pemanfaatan lahan pekarangan anggota, pelaksanaan menu B2SA dan pengembangan kebun sekolah.

2. Karakteristik anggota KWT penerima program KRPL di Kecamatan Bogor Barat sebagian besar berumur sedang atau dewasa yaitu 38-52 tahun (62\%), tingkat pendidikan responden tergolong rendah $(45 \%)$ responden adalah lulusan SD, sebagian besar responden memiliki jumlah anggota keluarga sedikit (56\%) dengan jumlah anggota 2-4 orang, dan lamanya tinggal diwilayah lokasi KRPL dalam kategori sedang yaitu 11-30 tahun (44\%).

3. Partisipasi anggota KWT dalam program KRPL di Kecamatan Bogor Barat termasuk kategori tinggi jumlah skor 6443 dengan rataan skor 2,62.

4. Faktor-faktor yang berhubungan nyata terhadap partisipasi anggota KWT dalam program KRPL di Kecamatan Bogor Barat adalah tingkat pendidikan, dukungan keluarga dan ketersediaan sarana dan prasarana. Faktor yang memiliki hubungan yang paling kuat adalah dukungan keluarga dengan nilai korelasi 0,635 dengan $(\mathrm{p}=0,01)$.

\section{Implikasi Kebijakan}

1. Meningkatkan peran dari warga masyarakat setempat dalam pelaksanaan program KRPL agar program ini tidak hanya sebatas dalam pelaksanaan tetapi benarbenar bermanfaat dan dapat berlanjut sehingga menyebar ke lokasi lain yang tidak mendapatkan program KRPL.

2. Membangun kesadaran, kerjasama dan rasa tanggung jawab bersama antar lembaga dan masyarakat yang ada diwilayah lokasi KRPL di Kecamatan Bogor Barat baik dalam memanfaatkan dan mengembangkan potensi tanaman pekarangan yang ada.

\section{DAFTAR PUSTAKA}

Azis, Turindra. 2009. Pengertian Partisipasi.

http://turindraatp.blogspot.com/200 9/ 06/pengertian-partisipasi.html [28 September 2013]. 
Badan Litbang Pertanian. 2012. Pengembangan Kawasan Rumah Pangan Lestari. Badan Penelitian dan Pengembangan Pertanian. Kementerian Pertanian. Jakarta. Badan Penelitian dan Pengembangan Pertanian. Kementerian Pertanian. Jakarta.

Badan Ketahanan Pangan. 2013. Pedoman Pelaksanaan Gerakan Percepatan Penganekaragaman Konsumsi Pangan (P2KP). Kementrian Pertanian. Jakarta.

Bambang, Heru. 2008. SkalaLikert. http://samianstats.wordpress.com/2 008/10/13. [19 Oktober 2013].

Departemen Pertanian. 1996. Pedoman Pembinaan Wanita Tani/Nelayan. Pusat Penyuluhan Pertanian Departemen Pertanian. Jakarta.

Irmayanti, Septria. 2011. Partisipasi Petani Dalam Program Pengembangan Usaha Agribisnis Pedesaan (PUAP) (Studi kasus Desa Sidourip dan Desa Pasar V Kebun Kelapa, Kec. Beringin. Kab. Deli Serdang) Skripsi. Fakultas Pertanian. Universitas Sumatera Utara. (diunduh 15 Oktober 2013)

Jannah, Miftahul dan Effendi. 2011. Partisipasi Petani dalam Program Rintisan dan Akselerasi Pemasyarakatan Inovasi Teknologi Pertanian (Prima Tani) di Kelurahan Lampake Kecamatan Samarinda Utara. Jurnal. Fakultas Pertanian Universitas Mulawarman. (diunduh 15 Oktober 2013).

Kantor Ketahanan Pangan Kota Bogor. 2013. Program Penganekaragaman Konsumsi Pangan (P2KP). 2012.

Mardikanto, Totok. 1991. Penyuluhan Pembangunan Pertanian. Surakarta: Sebelas Maret University Press.

Metalisa Rindi. 2011. Tingkat Partisipasi Wanita Tani dalam Kegiatan Kelompok tani di Kelurahan Korong Gadang Kecamatan Kuranji Kota Padang. Skripsi.
Fakultas Pertanian. Universitas

Andalas. Padang. (diunduh 15

Oktober 2013)

Monografi Kecamatan Bogor Barat. 2014. Kota Bogor

Sugiyono. 2011. Statistika untuk Penelitian. Alfabeta. Bandung. 